\title{
Physician, Know Thyself
}

Physician, heal thyself and know thyself. Most residency directors can to some degree intuit the attitudes, beliefs, and values of the residents in training and can to some degree respond to the residents' values systems.

The report by Saba, "What Do Family Physicians Believe and Value in Their Work?" in this issue of the $7 A B F P$ consists of qualitative and anecdotal research that reflects the heterogeneity among family practice residents. Saba studied the rich but varied religious, spiritual, and philosophical beliefs of 143 residents at the culturally diverse San Francisco General Hospital. The religious beliefs, values, and spiritual perspectives of the residents are based on the development, religious training, and life journey of each resident. This collage of different perspectives by Saba simply shows that the Tower of Babel exists.

We should all be aware that a heterogeneity of beliefs exists within any faith community. Among Protestants, Catholics, and Jewish people, there are those open to abortion, homosexuality, and the possibility of women providing leadership in the ministry, and there are those who are strongly opposed to each of these positions.

Similarly there is heterogeneity within the great religions in response to why bad things happen to good people. Many in the Judeo-ChristianIslamic belief systems see a connection between our behavior and the events that occur in our life. Others hold that life is more random. Harold Kushner, in his classic book, When Bad Things Happen to Good People, ${ }^{2}$ holds this latter view. If a gunman on the street sprays bullets, Kushner cannot believe that God has selected the 1 or 2 bystanders who are killed and the others who are unharmed. Kushner believes the event is random, that God is not micromanaging all events. Others will visit the homes of slain victims and will say that the deceased are at home with God, God has

Submitted 23 October 1998.

From Georgetown University School of Medicine, Washington, DC, and Brown University School of Medicine, Providence, RI. Address reprint requests to William Reichel, MD, 2205 Forest Ridge Road, Timonium, MD 21093-2917. brought them home; they were chosen to be brought home to their Lord.

Yet, in many instances a person's behavior brings on suffering and death, and those who view God's role as total accept such outcomes as punishing the acquired immunodeficiency syndrome victim or the lifelong smoker.

The Eastern religions offer a different explanation for the end of life as we know it. The Buddhist or Hindu expects to go on to another life that will manifest itself differently. They would express a more accepting world view of the tragic death of a 9-year-old in a car accident or other life situations that seem unfair.

Not only is there such great heterogeneity in the world's religions, but those who described themselves as atheists to Dr. Saba might hold strong spiritual and religious beliefs. In the 12step programs, for instance, there are those who do not want to use the word God for a higher power, but in many cases they are able to describe some type of belief in a higher power or spiritual presence. I have known persons who consider themselves agnostic or atheistic but who harbor a deep spiritual presence.

From all this diversity it is clear that the physician should, first, know thyself. The Recommended Core Educational Guidelines for Family Practice Residents in Medical Ethics, ${ }^{3}$ published by the American Academy of Family Physicians, wisely begins the knowledge component with, "The resident should develop knowledge of:

A. Belief systems, values, and biases

1. The physician's

2. The patient's

3. The family's

4. Influence of this belief system on decision making."

Only after the physician understands his or her belief system can that physician respect and show tolerance for the beliefs of the patient and the patient's family.

If you question 143 residents, 143 ethicists, 143 Americans, you will find many different perspectives. What can we learn from this cacophony of 
voices and thoughts? Physicians must understand themselves in each encounter with patients. We must approach all patients with universal principles that all the great religions and cultures and spiritual beliefs would agree upon. A EuropeanAmerican physician should be able to care for an African-American patient, a male physician should be able to care for a female patient, or a female physician should be able to care for a male patient. Universal tolerance should exist regardless of race, religion, national or ethnic background, or socioeconomic or educational status.

Some universal features are found among these religions and cultural groups. All religions in the world believe in compassion. On page 210 of Saba's article, a resident states, "There needs to be compassion... with passion...." The translation of compassion comes from the Latin, "with passion," referring to experiencing Jesus' suffering as experienced in Christianity. In each religion, in each culture and language, whether Judaism, Islam, Buddhism, or Hinduism, it is possible to trace the derivation of the same concept of compassion. Compassion can be replaced by the words "love or lovingkindness." Greek philosophers used the term "agape love" as opposed to other types of love such as "erotic love," and it is "agape love" that physicians can express to their patients.

It is remarkable that the Ten Commandments and the Golden Rule appear in similar forms in both Western and Eastern world religions. Again there are universal principles-do not steal, do not lie, do not kill, do not commit adultery.

Most of all, the family practice resident has the opportunity to base patient care on the universal principles of compassion, love, and respect. The resident and later the practitioner might have problems with a patient's sexual orientation, criminal past, or ethnic or religious heritage, but in becoming a good physician, these barriers must be set aside. Just as a physician must learn to deal with being attracted to patients of the opposite sex, disliking hypochondriacal, depressed elderly patients, or feeling hostile toward angry or demanding patients, the mature physician must also be able to care for patients who have widely varying philosophical and ethical beliefs. Attaining this degree of self-understanding and being able to care for patients and others with a nonjudgmental attitude should be part of medical student and resident training. An exceptional book that should be in the curriculum of medical students and residents is Respectful Treatment: A Practical Handbook of Patient Care by Martin Lipp. ${ }^{4}$

Although residents and family physicians might offer universal compassion, respect, and understanding, it is clear there will be times when the physician, while fully respecting the patient's beliefs and values, might not be able to support or recommend such procedures as abortion, assisted suicide, or other practices that would violate the physician's own belief system.

The Society of Teachers of Family Medicine "Recommended Core Educational Guidelines for Family Practice Residents on Culturally Sensitive and Competent Health Care," 5 is another resource for providing a greater understanding of cross-cultural differences and sensitivity. Culturally sensitive health care can be integrated into the family practice curriculum in the family practice center, hospital rounds, home visits, community fieldwork, conferences, and special parts of the behavioral science curriculum, such as Balint groups or videotape reviews, all of which prepare the family physician to have a greater understanding of the dynamics in the physician-patient relationship. Explicit psychosocial and behavioral training in residency will help nascent physicians to separate their own beliefs from others and to respect the beliefs and decisions of others.

William Reichel, MD

Georgetown University School of Medicine Washington, DC Brown University School of Medicine Providence, RI

\section{References}

1. Saba GW. What do family physicians believe and value in their work? J Am Board Fam Pract 1999; 12:206-13.

2. Kushner HS. When bad things happen to good people. New York: Schocken Books, 1981:46-55.

3. Recommended core educational guidelines for family practice residents in medical ethics. Kansas City, Mo: American Academy of Family Physicians, 1994.

4. Lipp MR. Respectful treatment-a practical handbook of patient care. 2nd ed. New York: Elsevier, 1986.

5. Like RC, Steiner RP, Rubel AJ. STFM core curriculum guidelines. Recommended core curriculum guidelines on culturally sensitive and competent health care. Fam Med 1996;27:291-7. 